\title{
THEORETICAL CONSIDERATIONS AND A SIMPLE METHOD FOR MEASURING ALKALINITY AND ACIDITY IN LOW-pH WATERS BY GRAN TITRATION
}

By Julia L. Barringer and Patricia A. Johnsson

U.S. GEOLOGICAL SURVEY

Water-Resources Investigations Report 89-4029

Prepared in cooperation with the NEW JERSEY DEPARTMENT OF ENVIRONMENTAL PROTECTION

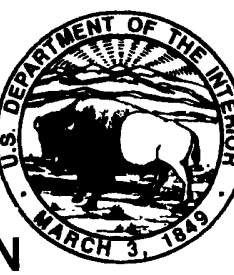

West Trenton, New Jersey 


\title{
U.S. DEPARTMENT OF THE INTERIOR \\ BRUCE BABBIT, Secretary
}

\author{
U.S. GEOLOGICAL SURVEY \\ Gordon P. Eaton, Director
}

For additional information

write to:

District Chief

U.S Geological Survey

Mountain View Office Park

810 Bear Tavern Road, Suite 206

West Trenton, NJ 08628
Copies of this report can be obtained from:

U.S Geological Survey

Earth Science Information Center

Open-File Reports Section

Box 25286, MS 517

Denver Federal Center

Denver, CO 80225 


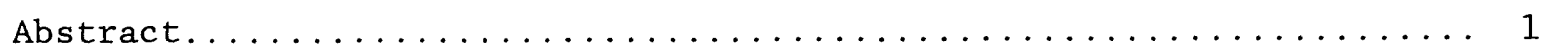

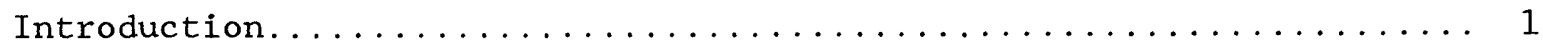

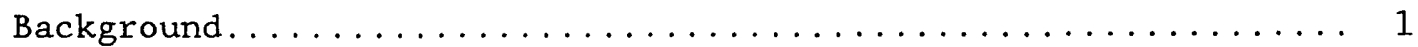

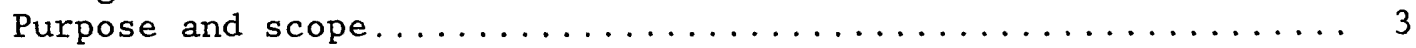

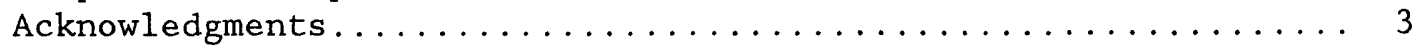

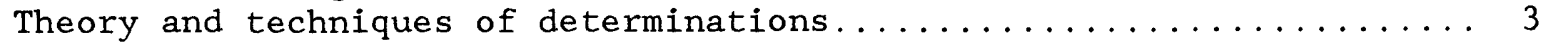

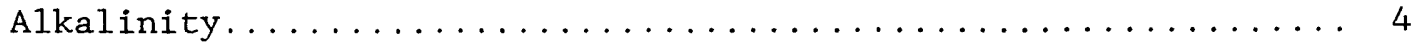

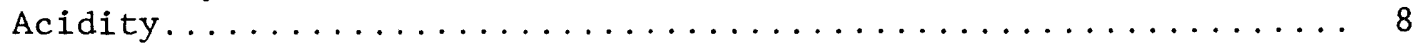

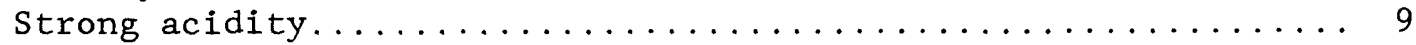

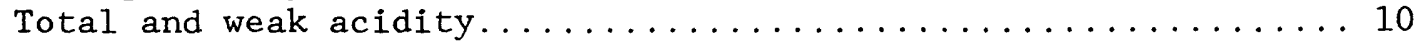

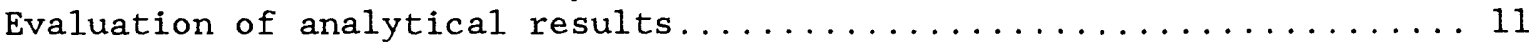

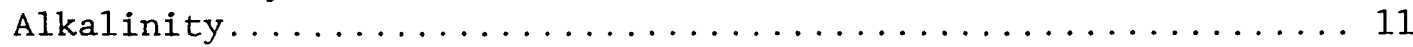

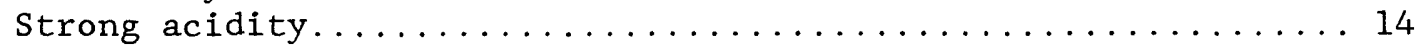

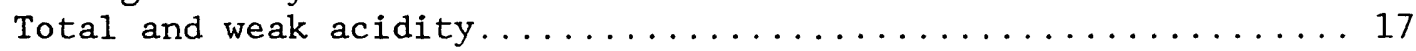

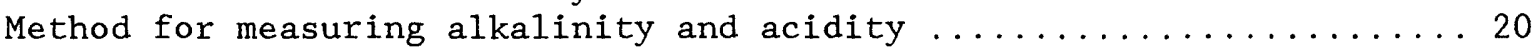

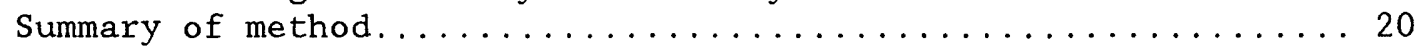

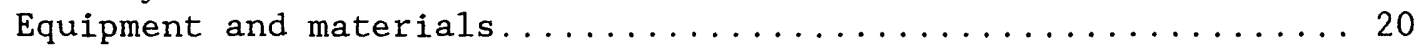

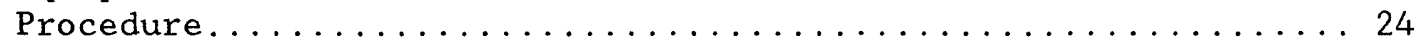

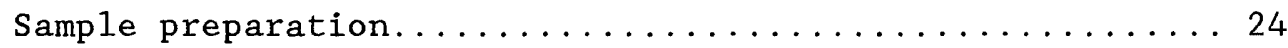

Calibration and preparation of equipment........... 25

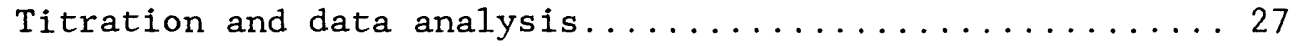

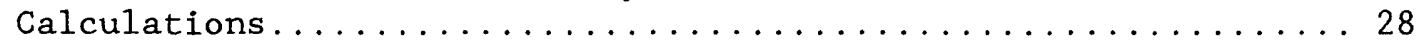

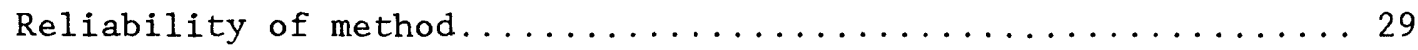

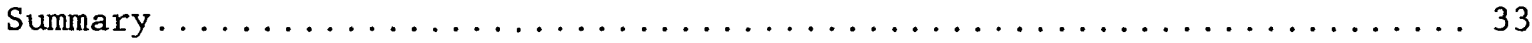

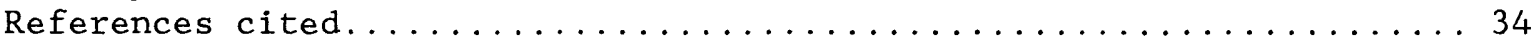

\section{ILLUSTRATIONS}

Figure 1a. Titration curves for alkalinity and strong acidity..... 7

1b. Typical Gran plot for alkalinity and strong acidity...... 7

2. Typical plot of Gran functions for strong acidity and

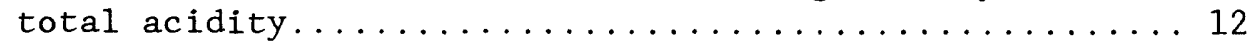

3. Acidity titration curves for deionized water, bulk precipitation, and surface water............ 15

4. Sketch of apparatus used in titration procedure........ 21

\section{TABLES}

Table 1. Percent difference between duplicate samples.......... 31

Table 2. Range of $\mathrm{pH}$, specific conductance, and dissolved organic carbon for duplicate samples................. 32 


\section{CONVERSION FACTORS AND ABBREVIATIONS}

Multiply

centimeter $(\mathrm{cm})$

millimeter $(\mathrm{mm})$

micrometer $(\mu \mathrm{m})$

kilogram $(\mathrm{kg})$

gram $(g)$

milligram (mg)

microgram $(\mu g)$

liter (L)

milliliter (mL)

degree Celsius $\left({ }^{\circ} \mathrm{C}\right)$
By

0.3937
0.03937
0.00003937
2.2046226
0.035273962
$0.000035273962-8$
$3.5273962 \times 10^{-8}$
33.81497
0.03381497
$1.8 \times\left({ }^{\circ} \mathrm{C}+32\right)$

To Obtain

inch

inch

inch

pounds, avdp

ounces, avdp

ounces, avdp

ounces, avdp

ounces, fluid

ounces, fluid

degree Fahrenheit $\left({ }^{\circ} \mathrm{F}\right)$

\section{Definitions}

A mole is a quantity containing Avogadro's number $\left(6.022 \times 10^{23}\right)$ of units (atoms, molecules). The number of moles of a substance can be calculated by dividing grams of the substance by the formula weight (atomic or molecular weight). The concentration of a substance in solution can be expressed in two ways: (1) the molarity of the solution (M), which is the concentration of the substance in moles per liter of solution; and (2) the molality of the solution $(\mathrm{m})$, which is the concentration of the substance in moles per kilogram of solvent. For dilute solutions (molarity $\leq 0.01$ ), molality is approximately equal to molarity.

An equivalent is a unit that expresses the combining capacity of a substance relative to a standard atom, usually hydrogen. A mole of an ion with a valence (charge) of 2 or greater represents a larger number of equivalents than does a mole of an ion with a valence of 1 . To convert moles of a substance to equivalents, multiply the number of moles by the valence.

The term "milliequivalents" is an abbreviation for milligram equivalents; therefore a milliequivalent is one-thousandth of an equivalent. A milliequivalent-per-1iter (meq/L) value may be calculated from a milligram-per-liter (mg/L) value by multiplying the milligram-per-liter value by the reciprocal of the combining weight (equivalent weight) of the ion. The equivalent weight is equal to the atomic or molecular weight divided by the valence.

Normality is defined as the number of equivalents of solute per liter of solution (eq/L). As an example of the difference between molarity and normality, a 6-molar solution of sulfuric acid $\left(\mathrm{H}_{2} \mathrm{SO}_{4}\right)$ is a 12 -normal solution, whereas a 6 -molar solution of hydrochloric acid (HC1) is a 6 -normal solution. 
THEORETICAL CONSIDERATIONS AND A SIMPLE METHOD FOR MEASURING

ALKALINITY AND ACIDITY IN LOW-pH WATERS BY GRAN TITRATION

by Julia L. Barringer and Patricia A. Johnsson

ABSTRACT

Titrations for alkalinity and acidity using the technique described by Gran (1952, Determination of the equivalence point in potentiometric titrations, Part II: The Analyst, v. 77, p. 661-671) have been employed in the analysis of low-pH natural waters. This report includes a synopsis of the theory and calculations associated with Gran's technique, and presents a simple and inexpensive method for performing alkalinity and acidity determinations. However, potential sources of error introduced by the chemical character of some waters may limit the utility of Gran's technique. Therefore, the cost-and time-efficient method for performing alkalinity and acidity determinations described in this report is useful for exploring the suitability of Gran's technique in studies of water chemistry.

\section{INTRODUCTION}

\section{Background}

Alkalinities and acidities of low-pH, low-ionic-strength natural waters are often difficult to measure accurately because some standard techniques may not be applicable. These standard techniques include two-point titrations for low-alkalinity samples and, for both alkalinity and acidity determinations, fixed-end-point titrations and incremental titrations with second-derivative calculations.

The two-point titration method for low-alkalinity samples (Greenberg and others, 1981) assumes a linear relation between volume of titrant added and change in $\mathrm{pH}$. This relation may not be linear in waters containing both strong and weak acids, and, thus, the technique may not be applicable to such waters. 
The fixed-end-point method, a widely used technique for alkalinity and acidity determinations, presents some specific difficulties when applied to low-pH waters. Alkalinity determinations by the fixed-end-point method are performed by lowering the $\mathrm{pH}$ of the sample with acid additions to the carbon-dioxide end point (or methyl-orange end point) of $\mathrm{pH} \mathrm{4.5.} \mathrm{This}$ method is based on the principle that when hydroxide, carbonate, and bicarbonate are the alkalinity-contributing species, carbon-dioxide concentration determines the $\mathrm{pH}$ at the equivalence point (Greenberg and others, 1981). A1though the method is straightforward for samples with $\mathrm{pH}$ greater than 4.5 , the titrations cannot be performed on samples with $\mathrm{pH}$ less than 4.5. The usefulness of the fixed-end-point method for acidity determinations also is limited by the sample chemistry. In acidity determinations, sample $\mathrm{pH}$ is raised by addition of base to the sodiumbicarbonate and sodium-carbonate equivalence-point $\mathrm{pH}$ values of 8.3 and 10.3, respectively. However, in samples that contain weak organic acids, the weak acids may not be fully titrated at these $\mathrm{pH}$ values.

The incremental titrations with second-derivative calculations are not useful in alkalinity determinations in low-pH waters with negative alkalinities. A negative alkalinity may be viewed as an alkalinity debt, where the sample contains so much acid that there are insufficient acidneutralizing species present. For samples with negative alkalinity (strong acid acidity), the second derivative method (Peters and others, 1974) cannot be used because the calculations cannot yield a negative result.

Gran's (1952) procedure bypasses most of the shortcomings of these techniques and has become a method of choice for low-pH, low-ionic-strength waters. (See, for example, Lee and Brosset, 1978; McQuaker and others, 1983; Driscoll and Bisogni, 1984; Lindberg and others, 1984). However, problems may arise with the application of Gran's technique to analyses of some low-pH, low-ionic-strength waters, particularly those waters with elevated concentrations of ammonium ion, organic acids, and/or aluminum and iron. Some of the problems have been discussed in the literature (Tyree, 1981; Driscoll and Bisogni, 1984; Keene and Galloway, 1985). However, difficulties and interferences other than those discussed in previous papers also may arise, and are addressed in this paper. 
There is currently no single reference that presents both a detailed methodology for performing Gran titrations and a comprehensive overview of the variety of analytical and interpretive difficulties that may be encountered in applying Gran's technique to a wide spectrum of low-pH waters. Stumm and Morgan (1981) present theoretical information for both alkalinity and acidity determinations by Gran titrations, but do not concentrate on the analytical procedures. There also is little detailed information on the equipment needed to perform Gran titrations. Apparatus employing manual equipment is described in Hillmann and others (1984). Automatic equipment is available through a variety of analytical instrument companies. However, this equipment typically is expensive, whether automatic or manual. Such equipment may be beyond the financial resources of the researcher who is exploring the application of Gran's technique.

\section{Purpose and Scope}

The purpose of this report is threefold: First, it gives an overview of the theory and calculations associated with Gran's technique in alkalinity and acidity determinations; second, it discusses the potential sources of error that can limit the applicability of the Gran technique to certain types of water samples; and, third, it presents an inexpensive method of performing incremental titrations for alkalinity and acidity.

\section{Acknowledgments}

Inspiration for the equipment setup described in this paper came from $M$. C. Yurewicz (U.S. Geological Survey, written commun., 1981). The suggestions and expertise of Robert F. Stallard, Geology Department, Princeton University (currently at the U.S. Geological Survey, Denver, Colo.), also were invaluable in the initial stages of the analyses.

\section{THEORY AND TECHNIQUES OF DETERMINATIONS}

In an aqueous system, alkalinity and acidity are the acid-neutralizing and base-neutralizing capacities, respectively, of the system. The conceptual chemical definitions of alkalinity and acidity are complementary, as are the techniques of determination. 


\section{Alkalinity}

Alkalinity represents the acid-neutralizing capacity of a given solution, and may be defined as the equivalent sum of all the bases that are titratable with a strong acid (Stumm and Morgan, 1981). For a monoprotic acid/base system, the alkalinity ( $A 1 k$ ) may be described by the charge balance equation

$$
\mathrm{A} 1 \mathrm{k}=\left[\mathrm{A}^{-}\right]+\left[\mathrm{OH}^{-}\right]-\left[\mathrm{H}^{+}\right]
$$

where square brackets [] denote concentration in moles per liter (after Stumm and Morgan, 1981, p.163). Where carbonate species are the primary weak acids and bases in natural waters, the alkalinity is expressed as

$$
\mathrm{Alk}=-\left[\mathrm{H}^{+}\right]+\left[\mathrm{OH}^{-}\right]+\left[\mathrm{HCO}_{3}^{-}\right]+2\left[\mathrm{CO}_{3}^{2-}\right]
$$

where $\mathrm{HCO}_{3}{ }^{-}$is the bicarbonate ion, and $\mathrm{CO}_{3}{ }^{2-}$ is the carbonate ion (Morel, 1983, p.137).

Low-pH natural waters may contain organic acids, the bases of which contribute to the alkalinity of the water. For such waters, the alkalinity equation includes the organic anion ( $\mathrm{RCOO}^{-}$) (Galloway and others, 1983), and may be expressed as

$$
\mathrm{A} 1 \mathrm{k}=\left[\mathrm{HCO}_{3}^{-}\right]+2\left[\mathrm{CO}_{3}^{2-}\right]+\left[\mathrm{OH}^{-}\right]+\left[\mathrm{RCOO}^{-}\right]-\left[\mathrm{H}^{+}\right] .
$$

In some low-pH waters, trivalent aluminum can be present in significant concentrations and can act as an acid. If the aluminum is present as hydroxide species, such as $\mathrm{Al}(\mathrm{OH})_{4}{ }^{-}, \mathrm{OH}^{-}$may be released to the solution as the $\mathrm{pH}$ decreases. Thus, Cosby and others (1985, p.154) gave an extended form of the alkalinity equation:

$$
\begin{aligned}
\mathrm{Alk}= & {\left[\mathrm{HCO}_{3}{ }^{-}\right]+2\left[\mathrm{CO}_{3}{ }^{2-}\right]+\left[\mathrm{OH}^{-}\right]+\left[\mathrm{Al}(\mathrm{OH})_{4}^{-}\right] } \\
& -\left[\mathrm{H}^{+}\right]-3\left[\mathrm{Al}^{3+}\right]-2\left[\mathrm{Al}(\mathrm{OH})^{2+}\right]-\left[\mathrm{Al}(\mathrm{OH})_{2}^{+}\right.
\end{aligned}
$$


The equations above demonstrate that the determination of alkalinity in some natural waters becomes a measurement of a variety of bases that will react with the acids present.

Gran (1952) developed a titration technique that could be applied to a variety of different chemical reactions. When used for alkalinity determinations, the technique involves incremental titration of the water sample with strong acid and calculation of the equivalent volume as a function of hydrogen-ion concentration and volume of titrant added. Driscoll and Bisogni (1984) presented a synopsis of the calculations involved in the alkalinity titration of a weak acid/base system. Part of these calculations is given below; the notation of Driscoll and Bisogni (1984) has been modified.

For a monoprotic acid/base system, HA, the alkalinity of the solution may be described by equation (1). As the sample is titrated with a strong acid of normality $\mathrm{C}_{a}$, the hydrogen-ion concentration will increase in solution and the weak conjugate base $\left[\mathrm{A}^{-}\right]$and the hydroxide-ion concentrations will decrease until the equivalence point is reached. The equivalence point is the point at which the concentration of the hydrogen ion $\left[\mathrm{H}^{+}\right]$equals the combined concentrations of the hydroxide ion $\left[\mathrm{OH}^{-}\right.$] and the conjugate base [ $\mathrm{A}^{-}$] of the acid HA. At this point the alkalinity is zero, as described by the equation

$$
\left[\mathrm{H}^{+}\right]=\left[\mathrm{A}^{-}\right]+\left[\mathrm{OH}^{-}\right]
$$

The volume of the titrant required to reach the equivalence point is called the equivalent volume $\left(\mathrm{V}_{\mathrm{eq}}\right)$. As the titration proceeds beyond the equivalence point, the alkalinity of the solution becomes negative, and the following approximations may be made (Driscoll and Bisogni, 1984):

$$
\left[\mathrm{H}^{+}\right] \gg\left[\mathrm{A}^{-}\right]+\left[\mathrm{OH}^{-}\right]
$$

and, therefore,

$$
\mathrm{Alk} \sim-\left[\mathrm{H}^{+}\right] \text {. }
$$


Gran (1952) demonstrated that the equivalent volume may be determined graphically by plotting a function of the hydrogen-ion concentration against the volume of titrant added. The plot will be a straight line, and the intersection of this line with the volume axis is the $v_{\text {eq }}$ (fig. 1).

The alkalinity of the solution may be calculated from the equivalent volume, using the equation

$$
\mathrm{Alk}=\mathrm{V}_{\text {eq }} \times \mathrm{C}_{\mathrm{a}} / \mathrm{V}_{\mathrm{o}}
$$

where

$$
\begin{aligned}
& \mathrm{V}_{\text {eq }}=\text { Equivalent volume of strong acid titrant, in liters (L); } \\
& \mathrm{C}_{\mathrm{a}}=\text { Normality of acid titrant, in equivalents per liter }\left(\text { eq } \mathrm{L}^{-1}\right. \text { ); } \\
& \mathrm{V}_{\mathrm{o}}=\text { Original sample volume, in liters (L). }
\end{aligned}
$$

(See Driscoll and Bisogni, 1984, for an expanded discussion).

In order to find the $\mathrm{V}_{\text {eq }}$, which is not directly measured by the Gran technique, the Gran function is calculated. The Gran function for alkalinity $\left(\mathrm{F}_{\mathrm{alk}}\right)$ is

$$
F_{a 1 k}=\left(V_{o}+v\right) \times 10^{-p H}
$$

which can be shown to be approximately equivalent to the equation

$$
F_{a l k}=\left(V-V_{e q}\right) \times C_{a}
$$

where

$$
\begin{aligned}
& V=\text { Volume of titrant added, in liters (Driscoll and Bisogni, } \\
& \text { 1984). }
\end{aligned}
$$

The $V_{\text {eq }}$ may be found by plotting $F_{\text {alk }}$ against $V$, and by extrapolating the linear part of the plot to $F_{a l k}=0$. However, the $V_{\text {eq }}$ may be found more accurately by using linear regression techniques to fit the data to a line described by the equation 


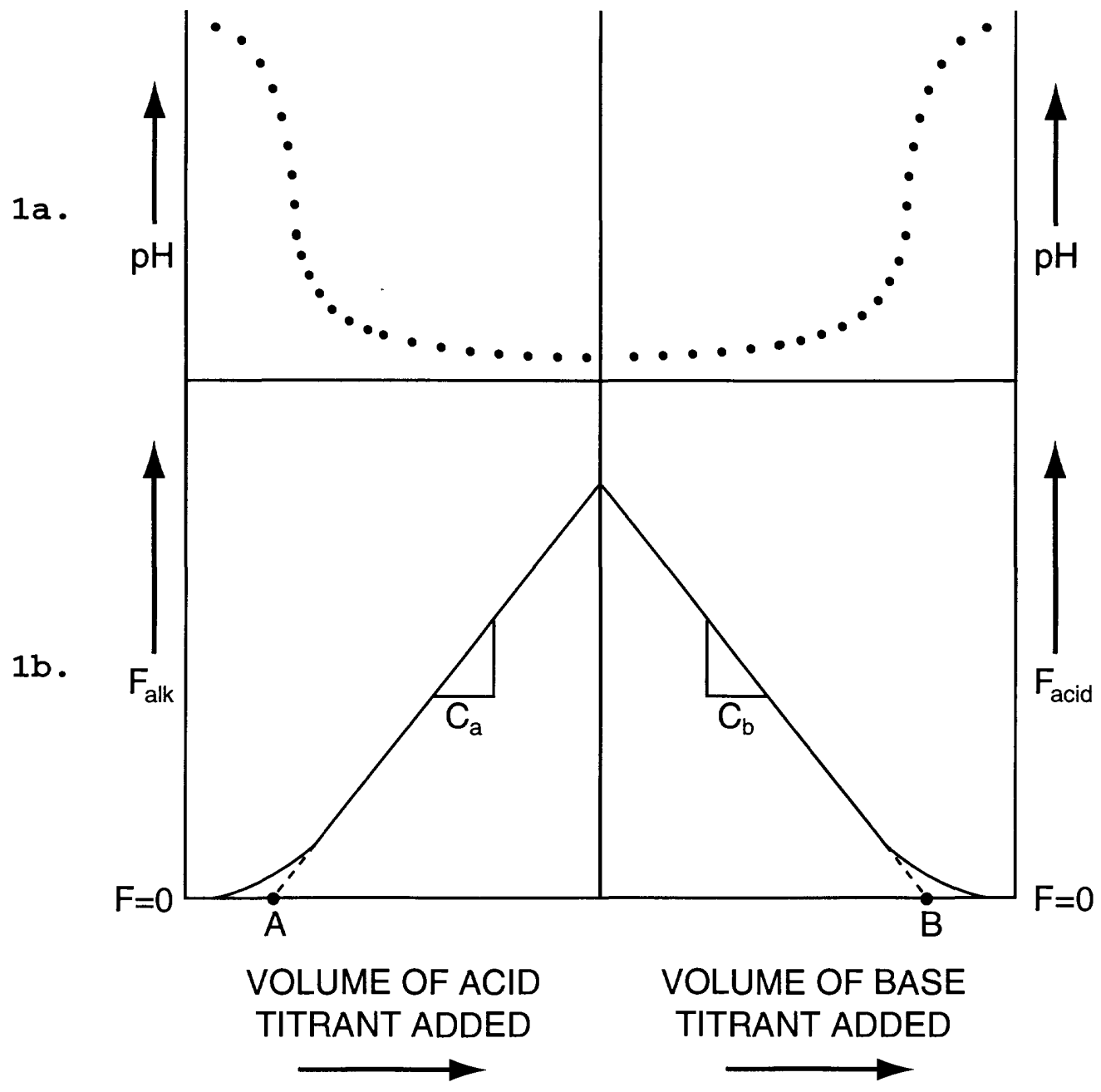

Figure 1a. Titration curves for alkalinity (left) and strong acidity (right) which would be associated with the Gran plots shown in fig. $1 b$.

Figure 1b. Typical Gran plot for alkalinity (left) and strong acidity (right). $F_{\text {alk }}$ and $F_{\text {acid }}$ are the Gran functions for alkalinity and strong acidity, respectively. The dashed lines to points $\mathrm{A}$ and $\mathrm{B}$ represent extrapolation of the linear portion of the Gran plot to the $x$ (volume)-intercept, where the Gran functions $F_{a l k}$ and $F_{\text {acid }}$ are both zero. Points $A$ and $B$ are the equivalent volumes $\left(V_{e q} s\right)$ for alkalinity and strong acidity, respectively. $C_{a}$ and $C_{b}$ are the normalities of the acid and base titrants, respectively, and are represented by the slope of the line. 


$$
F_{a l k}=b V+a
$$

where

$$
\begin{aligned}
a= & \text { the } y\left(F_{a l k}\right) \text { intercept, and } \\
b= & \text { the slope of the regression line, which is the same as the } \\
& \text { titrant normality } C_{a} .
\end{aligned}
$$

The $\mathrm{V}_{\text {eq }}$ is then the $\mathrm{x}(\mathrm{V})$-intercept (fig. $1 \mathrm{~b}$ ). The $\mathrm{V}_{\text {eq }}$ may be calculated using the following equation:

$$
v_{\text {eq }}=-a / b
$$

The correlation coefficient for the regression should equal or exceed 0.999 (Hillmann and others, 1984). If this criterion is not met, then the data should be considered to be inaccurate or of insufficient precision, and the titration should be performed again. Furthermore, the slope of the regression line (the normality of the titrant) should be within 10 percent of the known value (Hillmann and others, 1984, p.41) although, for some samples, this criterion will not be met. Variations in the slope of the regression line are discussed below.

\section{Acidity}

Acidity is the base-neutralizing capacity of a solution and may be defined as the equivalent sum of all the acids that are titratable with a strong base (Stumm and Morgan, 1981). The property of acidity may be subdivided into strong acidity (completely dissociated acids) and weak acidity (partially dissociated acids). Total acidity is the sum of strong and weak acidity.

When a strong acid is titrated by a strong base, the hydrogen-ion concentration will decrease until the equivalence point is reached. The graphical technique developed by Gran for calculating strong acidity is akin to the alkalinity technique discussed above. Natural waters are not simple 
systems, however, because they may contain both strong and weak acids. Johansson (1970) extended Gran's technique to a mixture of strong and weak acids, showing that Gran's method could be used with more complex solutions. This technique is thus applicable to a wide variety of natural waters.

\section{Strong Acidity}

The Gran technique can be used to determine the three types of acidity: total, strong, and by difference, weak. The acid that contributes to a $\mathrm{pH}$ of less than 4.5 has been referred to as mineral acidity (Pagenkopf, 1978, p. 100) or as strong or free acidity (Lindberg and others, 1984, p.186). As Lindberg and others (1984) point out, free acidity is the more accurate term because, in a system containing weak organic acids, the acidity comes from both strong (dissociated) and weak (partially dissociated) acids. However, in this paper the term "strong acidity" is retained to emphasize the contrast with weak acids in the calculations.

Strong acidity is determined by titrating with a strong base up to the midpoint $\mathrm{pH}$ in the titration curve, and by extrapolating from the linear region of the Gran plot to find the $V_{\text {eq }}$ (fig. $1 \mathrm{~b}$ ). The $V_{\text {eq }}$ also may be determined by linear regression. The equations and approximations involved are similar to those shown for the alkalinity determinations, and the Gran function for strong acidity ( $F_{\text {acid }}$ ) is calculated in the same manner. Although the slope of the Gran plot is negative because the Gran function decreases as $\mathrm{pH}$ increases, and titrant added (V) also increases (fig. 1b), the equation for the calculation of $F_{\text {acid }}$ is identical to that for $F_{a l k}$ :

$$
\mathrm{F}_{\text {acid }}=\left(\mathrm{V}_{\mathrm{o}}+\mathrm{V}\right) \times 10^{-\mathrm{pH}}
$$

The equation used to find the $\mathrm{V}_{\text {eq }}$ of strong acidity (Acid ${ }_{s}$ ) resembles the equation (8) used to calculate alkalinity:

$$
\operatorname{Acid}_{s}=v_{e q} \times C_{b} / v_{o} \text {, }
$$

where 


$$
\begin{aligned}
& \mathrm{v}_{\text {eq }}=\text { equivalent volume of strong base titrant }=-\mathrm{a} / \mathrm{b} \\
& \mathrm{C}_{\mathrm{b}}=\text { normality of base titrant, and } \\
& \mathrm{V}_{\mathrm{o}}=\text { volume of sample at beginning of acidity titration. }
\end{aligned}
$$

\section{Total and Weak Acidity}

Total acidity is determined by continuing the acidity titration with a strong base up to a high $\mathrm{pH}$ value. The equations and assumptions for total acidity are similar to those shown for alkalinity. However, the portion of the titration curve generated for total acidity will lie in the basic region $(\mathrm{pH}>7)$, where $\left[\mathrm{H}^{+}\right]$is negligible compared to $\left[\mathrm{OH}^{-}\right]$. Thus, hydroxide ion substitutes for hydrogen ion, or $10^{-\mathrm{pOH}}$ for $10^{-\mathrm{pH}}$.

The Gran Function $F_{\text {tacid }}$ for the total acidity portion of the titration, therefore, may be formulated as

$$
F_{\text {tacid }}=\left(V_{o}+V\right) \times 10^{-p O H}
$$

Total-acidity equivalents $\left(\operatorname{Acid}_{t}\right.$ ) are determined in the same manner as the strong-acidity equivalents:

$$
\text { Acid }_{t}=v_{\text {eq }} \times C_{b} / v_{o}
$$

where

$$
\begin{aligned}
& \mathrm{V}_{\text {eq }}=\text { equivalent volume of strong base titrant }=-\mathrm{a} / \mathrm{b} \\
& \mathrm{C}_{\mathrm{b}}=\text { normality of base titrant, and } \\
& \mathrm{v}_{\mathrm{o}}=\text { volume of sample at beginning of acidity titration. }
\end{aligned}
$$

When total acidity (in equivalents per liter) has been determined, weakacidity equivalents are calculated by taking the difference between totaland strong-acidity results. This procedure is shown graphically in 
figure 2, where the gap between the extrapolated $\mathrm{V}_{\text {eq }} \mathrm{s}$ (B-C) represents the weak-acidity component. If the solution contained only strong acid, then the $\mathrm{V}_{\text {eq }}$ for strong acidity would be the same as that for total acidity.

EVALUATION OF ANALYTICAL RESULTS

\section{Alkalinity}

The usefulness of Gran titrations for alkalinity may be limited by the chemistry of a given sample as well as by the range of $\mathrm{pH}$ values used in the calculations. For water samples that contain only carbonate species, determination of alkalinity generally is straightforward, except when significant outgassing of carbon dioxide leads to instability of sample $\mathrm{pH}$. Accurate calculation of the Gran function $\mathrm{F}_{\mathrm{alk}}$ depends on accurate measurements of $\mathrm{pH}$. Instability of sample $\mathrm{pH}$ makes such measurements difficult.

The $\mathrm{pH}$ of a solution is affected by changes in the concentration of dissolved carbon dioxide $\left(\mathrm{CO}_{2}\right.$ (gas)), according to the equation

$$
\mathrm{CO}_{2} \text { (gas) }+\mathrm{H}_{2} \mathrm{O}=\mathrm{H}_{2} \mathrm{CO}_{3} \text {, }
$$

where carbonic acid $\left(\mathrm{H}_{2} \mathrm{CO}_{3}\right)$ is formed, and the equation

$$
\mathrm{H}_{2} \mathrm{CO}_{3}=\mathrm{H}^{+}+\mathrm{HCO}_{3}^{-}
$$

where carbonic acid dissociates to form bicarbonate ion $\left(\mathrm{HCO}_{3}{ }^{-}\right)$and hydrogen ion. Alkalinity is generally conservative with respect to $\mathrm{CO}_{2}$ because, for each hydrogen ion produced, a bicarbonate ion also is produced. However, in trace-metal-rich waters, outgassing of $\mathrm{CO}_{2}$ may cause a solid phase to precipitate. For example, when $\mathrm{CO}_{2}$ outgasses from iron-rich waters, the accompanying $\mathrm{rise}$ in $\mathrm{pH}$ can cause iron hydroxide $\left(\mathrm{FeOH}_{3}\right)$ to form. This removes hydroxyl ion from the sample and alters the alkalinity. 


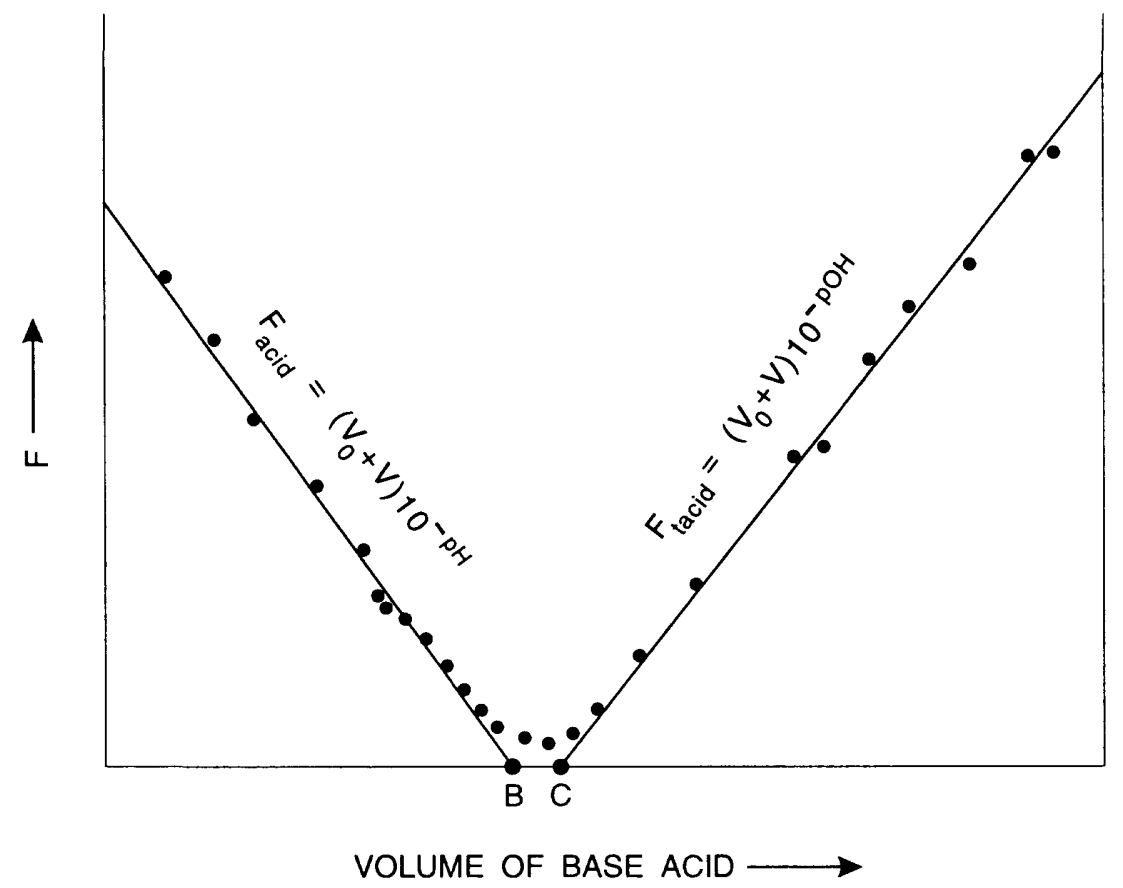

Figure 2. Typical plot of Gran functions $\left(F_{\text {acid }}\right.$ and $F_{\text {tacid }}$ ) for strong acidity $\left\{\left(\mathrm{V}_{\mathrm{o}}+\mathrm{V}\right) 10^{-\mathrm{pH}}\right\}$ and total acidity $\left\{\left(\mathrm{V}_{\mathrm{o}}+\mathrm{V}\right) 10^{-\mathrm{pOH}}\right\} . \mathrm{V}_{\mathrm{o}}$ is the original volume of the sample at the beginning of the titration; $\mathrm{V}$ is the volume of titrant added. Points $B$ and $C$ are the respective equivalent volumes $\left(V_{e q} s\right)$. The gap between the $V_{e q} s$ (B-C) represents the weak acidity contribution. The dots represent hypothetical data points. Similar plots may be found in Molvaersmyr and Lund (1983) and Lindberg and others (1984). 
Hydrolyzable metal ions, such as iron and aluminum species, can contribute to the measured alkalinity, exerting a buffering effect on a sample during titration. As the $\mathrm{pH}$ of a solution decreases during titration, the dissociation of metal-hydroxide species releases hydroxyl ions that will be measured as part of the solution's alkalinity.

Some natural waters contain organic substances (humic and fulvic acids) that can contribute weak bases to the solution. The presence of weak bases in the system is a potential source of error in the alkalinity analysis (Driscoll and Bisogni, 1984). Weak bases will participate in the alkalinity titration at the outset, but, as the $\mathrm{pH}$ decreases, the weak acids present will be increasingly less dissociated.

An average $\mathrm{pK}_{\mathrm{a}}{ }^{1}$ for humic substances may be approximately 4.2 , but individual organic acids can have $\mathrm{pK}_{\mathrm{a}} \mathrm{s}$ ranging from 1.2 (oxalic acid) to 4.8 (simple aliphatic acids) (Thurman, 1985, p. 90). Where $\mathrm{pH}=\mathrm{pK}_{\mathrm{a}}$, the acid will be 50 percent dissociated. Acidic natural waters typically have $\mathrm{pH}$ values in a range that encompasses the $\mathrm{pk}_{\mathrm{a}}$ values determined for a variety of weak organic acids. Therefore, any dissociated weak organic bases that may be present will buffer the system at the onset of the alkalinity titration. Assuming an average $\mathrm{pk}_{\mathrm{a}}$ of 4.2, organic acids still may be about 20 percent dissociated at a $\mathrm{pH}$ of 3.5 (depending on type and concentration of acid, and solution ionic strength). These acids probably will be less than 10 percent dissociated when a $\mathrm{pH}$ of 3.0 is reached, and the buffering effect of the weak bases will be small.

The initial buffering effect of the weak bases results in lower values of $\mathrm{F}_{\mathrm{alk}}$ calculated for data generated at the beginning of the titration, and a concomitant decrease in the slope of the regression line. If the slope of the line is lower, the intercept, and therefore the extrapolated $v_{\text {eq }}$ also will be a lower value. If a lower value of the equivalent volume $\left(V_{e q}\right)$ is determined, the alkalinity measurement will be underestimated (Driscoll and Bisogni, 1984, p.57).

\footnotetext{
$1_{\text {The expression }} \mathrm{pk}_{\mathrm{a}}$ represents the negative logarithm of an acid dissociation constant $\mathrm{K}_{\mathrm{a}}$.
} 
A judicious choice of the $\mathrm{pH}$ range used for the Gran calculations may circumvent much of the error introduced by the presence of weak bases. Driscoll and Bisogni (1984, p.58) found that data from a $\mathrm{pH}$ range between 3.0 and 4.0 gave the best match between measured and theoretical values. They concluded that "to minimize weak base error in solutions it is best to evaluate the Gran function over a $\mathrm{pH}$ range as far below solution protondissociation constants as possible."

Metal ions can form complexes with organic material and thus have the potential for affecting the behavior of weak organic acids in solution. Driscoll and Bisogni (1984, p.64) found that proton dissociation constants for organic acids were lower in acidic waters than in those with nearly neutral $\mathrm{pH}$ and suggested the decrease was due to "the association of hydrolyzable aluminum with natural organic matter" in acidified waters. Thus organically bound aluminum may participate in the weak acid/base character of such waters.

The foregoing discussion has given an overview of the complexity of alkalinity measurements in many low-pH natural waters. The alkalinity value that is determined for such waters represents a total alkalinity measurement rather than bicarbonate alkalinity because bases other than bicarbonate will have been titrated.

\section{Strong Acidity}

Problems similar to those inherent in alkalinity titrations of acidic, metal-rich, and/or organic-rich waters are present in the determinations of "strong" acidity. Buffering by weak acids during an acidity titration is analagous to the weak-base buffering encountered in some alkalinity determinations ( $\mathrm{fig} .3$ ). As base titrant is added during the acidity titration the $\mathrm{pH}$ rises, causing weak acids, which may be partially dissociated, to dissociate further. The weak-acid dissociation results in an overestimation of the strong acidity (Keene and Galloway, 1985). The effect of the weak acid dissociation may be minimized by performing the strong-acidity portion of the titration over a $\mathrm{pH}$ range in which the dissociation of weak acids will be negligible. Some researchers have added 

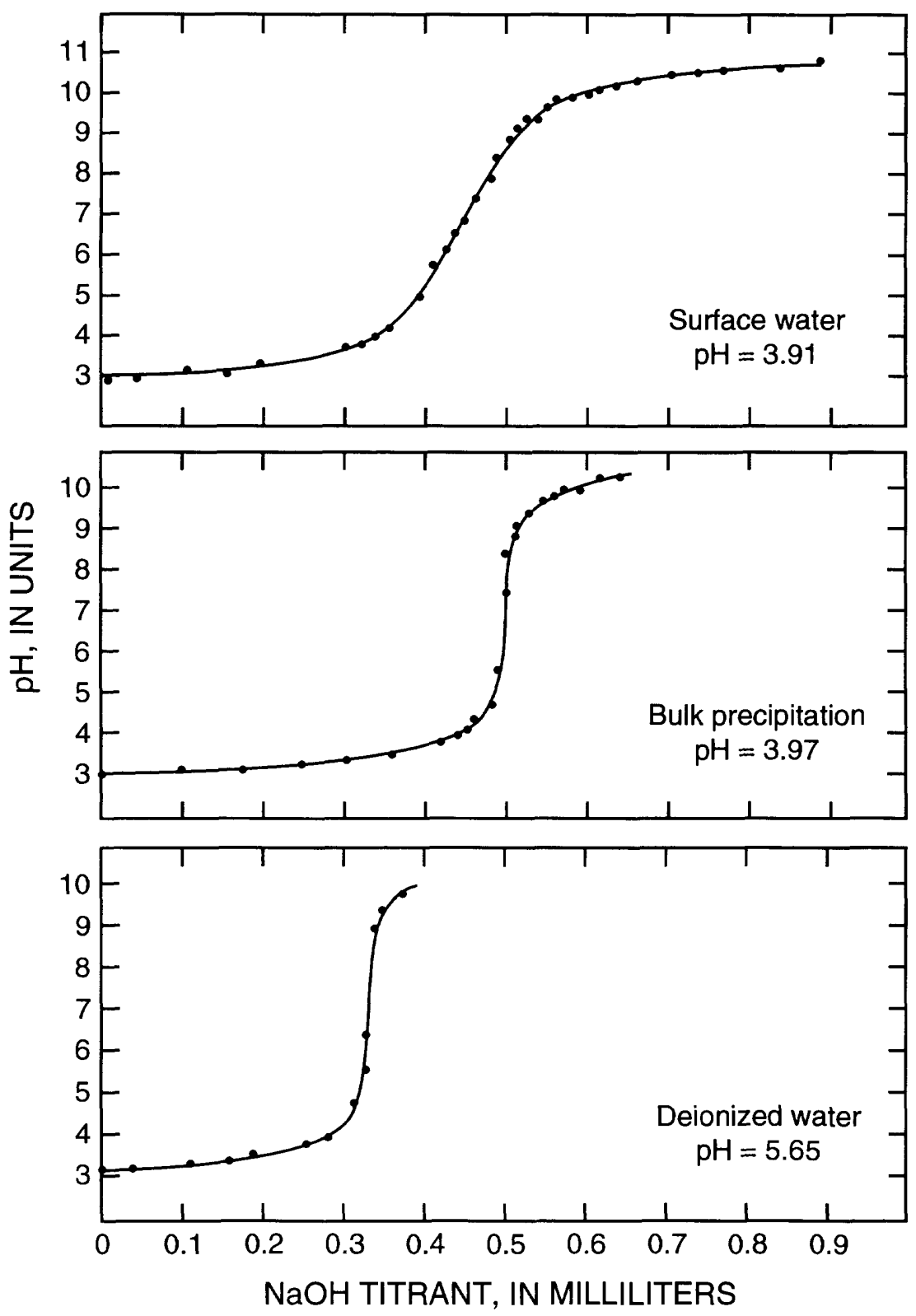

Figure 3. Acidity titration curves for deionized water, bulk precipitation, and surface water from headwaters of McDonalds Branch, Burlington County,

New Jersey. All three samples were back-titrated with sodium hydroxide following an alkalinity titration with hydrochloric acid. The surface-water sample contains weak organic acids which buffer the system, resulting in a flattened titration curve. 
a single volume of strong acid to the sample to permit the base titration to begin with mostly undissociated weak acids present (Lee and Brosset, 1978). However, Lindberg and others (1984, p.189) suggest titrating with a strong acid prior to the base titration. Such a titration, which involves titrating away from the original sample $\mathrm{pH}$ and then, with change of titrant, titrating back through the sample $\mathrm{pH}$ is referred to as "back-titration." Back-titration is the technique described in this report for acidity determinations.

Lowering $\mathrm{pH}$ by performing an alkalinity titration is a more efficient means of gathering data than lowering sample $\mathrm{pH}$ with a single addition of acid. Using the equipment described below, an alkalinity titration takes 15 minutes or less, and adding strong acid as a single volume takes about 1 minute. In this study, for back-titration of samples in equilibrium with the atmosphere, the slight increase in time did not appear to affect reproducibility.

A second advantage of commencing the acidity titration at a $\mathrm{pH}$ below that of the original sample is that hydrolyzable metal ions such as aluminum and iron will be less likely to be present as hydroxides. As base titrant is added, hydroxyl ions will begin to react with the metals, forming metal hydroxides. If only the data generated at the beginning of the titration are used in calculating the strong-acidity Gran function, the buffering effect of the metal hydroxides will be minimized. Hot hydrogen peroxide treatment of samples containing hydrolyzable metal ions has been suggested as a means of counteracting the hydrolysis effect (Greenberg and others, 1981 , p. 250). However, the peroxide will oxidize any organic material present, and heating will release dissolved $\mathrm{CO}_{2}$. Although it is possible that a combination of this treatment with standard Gran titrations might be useful, to the authors' knowledge such a procedure has not been reported. Fractionation procedures for determining the contributions of both aluminum and organic matter to titrations are discussed by Thurman and Malcolm (1981); Driscoll and Bisogni (1984); and Driscoll (1984). Fractionation procedures combined with the Gran technique should yield more refined data. 
The volume of acid titrant added is small relative to the original volume of the sample. Therefore, a back-titration for strong acidity should produce a titration curve that is almost identical to that generated in the alkalinity titration, if the acid and base titrants have the same normality. However, reactions involving esters may produce hysteresis in the titration curves for organic-rich samples (J.A. Leenheer, U.S. Geological Survey, oral commun., 1986). In the calculations for strong acidity, if back-titration is used, the original volume $\left(V_{0}\right)$ should include the volume of acid titrant added during the alkalinity titration. The calculated $V_{\text {eq }}$ for strong acid also must be adjusted for the volume and normality of the acid titrant added. The calculations are simplified if both acid and base titrants have the same normality.

\section{Total and Weak Acidity}

The presence of ammonium ion in some samples may lead to erroneous results for the total acidity determination (Tyree, 1981, p.58; Keene and Galloway, 1985, p.202) and, thus, to an overestimation of the weak acidity component. This problem may be encountered in precipitation samples affected by industrial or agricultural activities. The buffering effect of ammonium ion is seen increasingly at higher $\mathrm{pH}$ values, inasmuch as the equilibrium constant for the reaction

$$
\mathrm{NH}_{4}^{+}=\mathrm{NH}_{3}+\mathrm{H}^{+}
$$

is $5.6 \times 10^{-10}$, which gives a pK of 9.25 (Tyree, 1981, p.57). If the ammonium concentration of a given sample is known, and if the titration has been carried out to sufficiently high $\mathrm{pH}$ values, then the equivalents of $\mathrm{NH}_{4}{ }^{+}$may be subtracted from the equivalents of total acidity determined. The presence of ammonium ion should be suspected in precipitation samples where high values for weak acidity are determined. Other types of water samples may require correction for ammonium ion as well.

Silicic acid $\left(\mathrm{H}_{4} \mathrm{SiO}_{4}\right)$ is a weak acid which may be present in surfacewater, soil-water, ground-water, and throughfall samples. With a first dissociation constant of $1 \times 10^{-9.9}$ (Drever, 1982, p.91), silicic acid 
will begin to dissociate to form $\mathrm{H}_{3} \mathrm{SiO}_{4}{ }^{-}$at a $\mathrm{pH}$ of about 8 . At a $\mathrm{pH}$ near 10, $\mathrm{H}_{3} \mathrm{SiO}_{4}^{-}$, with a dissociation constant of $1 \times 10^{-11.7}$ (Drever, 1982, p. 91), also will begin to dissociate to form $\mathrm{H}_{2} \mathrm{SiO}_{4}{ }^{2-}$. The polyprotic silicic acid continues to dissociate at $\mathrm{pH}$ values greater than 12 , although the amounts of hydrogen ion contributed should be negligible.

The total dissolved silica $\left(\mathrm{SiO}_{2}\right)$ concentration of a given water may be written as the sum of ionized and un-ionized species, as follows:

$$
\left(\mathrm{m}_{\mathrm{SiO}_{2}}\right)_{\mathrm{T}}=\mathrm{m}_{\mathrm{H}_{4}} \mathrm{SiO}_{4}+\mathrm{m}_{3} \mathrm{SiO}_{4}-+\mathrm{m}_{\mathrm{H}_{2} \mathrm{SiO}_{4}}{ }^{2-}
$$

where $\mathrm{m}=$ molal concentration (Drever, 1982, p.91).

The activity of silicic acid in solution may not be as high as the total dissolved silica concentration might indicate, because polymeric silicate ions also may be present (Drever, 1982, p.91). However, an estimate of the silicic acid component of the weak-acidity determination can be made.

In aluminum- and iron-rich waters, hydroxides of these metals may form during the course of an acidity titration, consuming hydroxyl ions that would otherwise neutralize acids in solution. As Keene and Galloway (1985) point out, the presence of constituents that react with $\mathrm{OH}^{-}$will result in an overestimate of total acidity. Reactions involving the formation of metal hydroxides should be suspected if the value of the slope of the regression line for the Gran function ( $F$ ) on $V$ is greater than the value of the base titrant normality. This effect has been observed in surface- and soil-water samples from the New Jersey Pinelands analyzed during the course of this study.

Insofar as the weak-acidity value is calculated by subtracting strong acidity from total acidity results, the effect of hydroxide formation will be seen as an overestimate of the weak acidity component as well. If dissolved aluminum and iron concentrations are known for a given sample, the 
use of geochemical models such as WATEQF (Plummer and others, 1978) or ARCHEM (Johnsson and Lord, 1987) may permit an estimate of the metal hydroxide contribution to the weak acidity value.

For samples containing a variety of weak acids, the acidity titration should be continued until the acids are completely dissociated. Molvaersmyr and Lund (1983, p.306) titrated samples to a $\mathrm{pH}$ of 10.3. Depending on the individual sample, it may be necessary to titrate to a higher $\mathrm{pH}$. Changes in $\mathrm{pH}$ per increment of titrant added may not become sufficiently small for acceptable linear regression results until a pH of 10.0 or higher, especially in organic-rich samples. Further, the organic acids present may not be completely dissociated at a pH of 10.0 .

Structures and compositions of naturally occurring organic acids (humic and fulvic) are imperfectly known at present. Thus, the behaviour of organic acids during titration is not understood in detail, although estimates have been made. In their study of organic-rich bog waters, McKnight and others (1985, p.1345) assumed that carboxylic acid groups would be completely titrated when a $\mathrm{pH}$ of 8 was reached, and that approximately one-half of the phenolic groups would be titrated in the $\mathrm{pH}$ range of 8 to 10 . The phenolic groups probably are too weakly acidic to affect the acid/base status of strongly acidic natural waters, as the $\mathrm{pk}_{\mathrm{a}}$ range for phenolic groups is from 9.0 to 11.0 (McKnight and others, 1985, p. 1345). However, phenolic groups will dissociate during the total acidity titration and will constitute part of the total and weak acidity determinations. For water samples containing a single weak acid, the concentration and $\mathrm{pK}$ may be calculated using the change in slope of a Gran plot (Lee and Brosset, 1978). For samples containing a mixture of inorganic and organic weak acids, the organic-acid contribution to the weak-acidity value may be calculated using the method of Oliver and others (1983).

The researcher must have an adequate understanding of the chemistry of the samples to be analyzed in order to plan an appropriate titration strategy. If the water samples contain any of the species discussed above, the total-acidity portion of the titration should be carried out to a $\mathrm{pH}$ that will insure the dissociation of those weak acids that contribute 
significantly to the acidity of the sample. However, useful pH data may be difficult to generate near the end of the titration, given the limited resolution of most $\mathrm{pH}$ meters in a range in which $\mathrm{pH}$ changes very little for each increment of base titrant added.

METHOD FOR MEASURING ALKALINITY AND ACIDITY

\section{Summary of Method}

The procedure described below is composed of four parts. An alkalinity titration with strong acid titrant is followed by a back-titration with a strong base titrant for strong and total acidity. The raw data are edited so that only the data from the extremes of the $\mathrm{pH}$ ranges are used for the linear regressions. Finally, calculations are performed to yield values for alkalinity, strong acidity, total acidity, and weak acidity.

\section{Equipment and Materials}

The procedure outlined below, while involving inexpensive equipment, can produce accurate determinations of both alkalinity and acidity. The $\mathrm{pH}$ meter should measure to $\pm 0.01 \mathrm{pH}$ unit, and the microburette, pipettor or titrator should deliver 0.01 to $0.05 \mathrm{~mL}$ (milliliter) with \pm 1 -percent accuracy (Hillmann and others, 1984, p. 24). A Ag/AgCl (silver/silver chloride)-type combination electrode was used in the apparatus described below. In solutions containing $\mathrm{NaOH}$ (sodium hydroxide) titrant, an epoxybody electrode should prove more durable than one with a glass body ( $R$. F. Stallard, Princeton University, oral commun., 1985).

Figure 4 shows the equipment apparatus, which includes the following:

(a) a Beckman ${ }^{2}$ Phi 21 digital pH meter, (b) a Beckman Futura II

\footnotetext{
2 The use of trade, brand, and firm names in this report is for identification purposes only and does not constitute endorsement by the U.S. Geological Survey.
} 


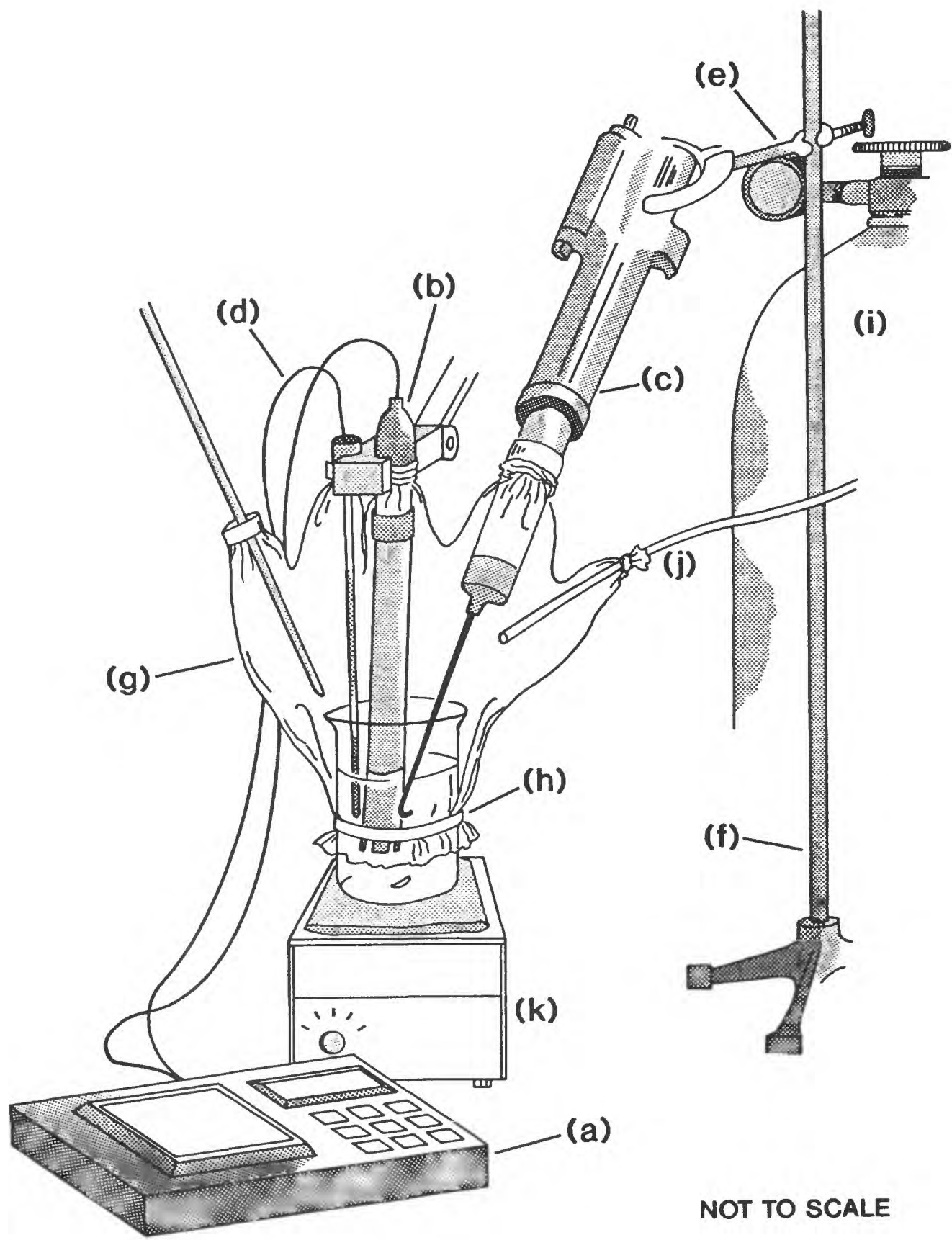

Figure 4. Sketch of apparatus used in titration procedure: (a) Beckman Phi 21 digital $\mathrm{pH}$ meter; (b) Beckman Futura II combination electrode with epoxy body; (c) Hach digital titrator with cartridge and a j-shaped delivery tube; (d) Beckman temperature probe; (e) adjustable support arm; (f) support rod; (g) clear vinyl lab glove; (h) 100-milliliter beaker with 12.7-millimeter Teflon stir bar on a styrofoam pad; (i) tank of ultrapure nitrogen with regulator; (j) inlet tube secured to the thumb of the glove; (k) stirrer. 
combination electrode with epoxy body, (c) a Hach digital titrator with cartridge and a $\mathbf{j}$-shaped delivery tube, (d) a Beckman temperature probe, (e) an adjustable support arm, (f) a support rod, (g) a clear vinyl lab glove with finger ends cut off and reinforced with masking tape, (h) a 100 $\mathrm{mL}$ beaker with a $12.7-\mathrm{mm}$ (millimeter) Teflon stir bar, on a styrofoam pad (to reduce heat buildup from the stirrer beneath), and (i) a tank of ultrapure nitrogen with $(j)$ the inlet tube secured to the thumb of the glove with a rubber band.

Acidity titrations typically are carried out under an inert atmosphere of $\mathrm{CO}_{2}$-free argon or nitrogen. Ambient atmosphere should be excluded, because the sample may react with atmospheric $\mathrm{CO}_{2}$ as the added base titrant causes the $\mathrm{pH}$ to increase above 7 . The titrant $(\mathrm{NaOH})$ also will react with atmospheric $\mathrm{CO}_{2}$ and therefore must be stored with no headspace or under a vacuum or an inert gas. An inert atmosphere also reduces the opportunity for metal hydroxides to precipitate during the acidity titration. Although some researchers prefer to perform alkalinity titrations under an inert atmosphere, this may not be necessary for low-pH samples. The U.S. Geological Survey's procedure for alkalinity determinations (Laboratory Method I-2034.86 approved 1-10-86) by the Gran technique, using an automated titrator, calls for performing the analyses under an inert gas ( $\mathrm{H}$. Feltz, U.S. Geological Survey, oral commun., 1986). In this study, for samples that were in equilibrium with the atmosphere (precipitation, throughfall, and surface water), alkalinity titrations performed under nitrogen and in the ambient atmosphere produced values that were comparable to each other. For those samples (primarily soil solution and ground water) in which the partial pressure of $\mathrm{CO}_{2}$ may be greater than atmospheric, outgassing of the sample during titration will not be prevented by the nitrogen atmosphere.

In general, ultra-high-purity grade nitrogen, which is virtually free of $\mathrm{CO}_{2}$ impurities, is less expensive and more readily available than argon, and, because nitrogen is a lighter gas, it is more easily vented. Although nitrogen is a nonpoisonous gas, the amount that leaks from the "glove bag" shown in figure 4 could cause anoxia under poorly ventilated conditions. The equipment should be placed in a fume hood. 
The small "glove bag" shown in figure 4 is easier to use and more economical than the larger, conventional glove bags. With the conventional glove bag, several samples can be set up for titration without intervening evacuation. However, the conventional glove bag is awkward to use, requires a larger volume of gas to maintain an inert atmosphere, and involves a major undertaking to correct any operational problems or errors. The small glove bag generally lasts for 10 to 12 titrations before replacement is required.

Microburettes, micropipettors, and digital titrators are widely available. Positive-displacement titrators have an advantage over airdisplacement micropipettors because they offer flexibility in the amount of titrant to be added at any given time. A digital display indicates the amount of titrant delivered; therefore, any irregularities in titrant delivery can be noted. However, if the analyst fails to empty the chamber of a micropipettor with fixed-volume delivery, the actual amount delivered is not known.

For low-pH waters, hydrochloric acid ( $\mathrm{HCl}$ ) is an appropriate acid titrant. A $50.0-$ or $75.0-\mathrm{mL}$ volume of sample is convenient to use, and either 0.10 - or $0.16 \mathrm{-N}$ (normal) titrant is appropriate to those volumes. It is convenient to use base and acid titrants of the same normality, so that raw data from the alkalinity and strong acidity titrations can be compared and problems noted early in the procedure. The base titrant used in the procedure described below was $0.1600-\mathrm{N} \mathrm{NaOH}$, supplied in titrator cartridges by the Hach Company.

Sulfuric acid $\left(\mathrm{H}_{2} \mathrm{SO}_{4}\right)$ also has been used for alkalinity titrations, but because it is a diprotic acid with a $\mathrm{K}_{\mathrm{a} 2}$ of $1.20 \times 10^{-2}$ (Weast and others, 1988-1989, Section D, p. 163), it can introduce an error if it is used as the acid titrant for low-pH waters. If the sample is titrated down to a $\mathrm{pH}$ lower than 4 , the weak acid $\mathrm{HSO}_{4}{ }^{-}$will be increasingly less likely to be completely dissociated as the $\mathrm{pH}$ decreases. The error introduced by the use of $\mathrm{H}_{2} \mathrm{SO}_{4}$ titrant appears to be about 2 percent of the alkalinity value determined. 


\section{Procedure}

\section{Sample Preparation}

Samples should be chilled upon collection, stored in the dark, and titrated as soon as possible thereafter. All samples analyzed in this study were filtered through 0.45-micrometer filters. Fishman and Friedman (1985) indicate that alkalinity and acidity may not be stable for longer than a few hours, and analyses should be performed promptly. However, studies conducted by the U.S. Geological Survey indicate that, for chilled samples (collected from waters in equilibrium with the atmosphere) that have been filtered through 0.2-micrometer Nucleopore filters, alkalinity is stable for longer periods of time (M. Kennedy, U.S. Geological Survey, oral commun., 1985).

Although the alkalinity or acidity of a sample may not change with temperature changes, inconsistency in the $\mathrm{pH}$ measurements is likely to lead to inaccurate results when the regression is performed on the data. If the sample is taken chilled and permitted to warm during the titration, the $\mathrm{pH}$ values will not be comparable--for a given sample, the $\mathrm{pH}$ value will be higher at $4{ }^{\circ} \mathrm{C}$ (degrees Celsius) than at $25^{\circ} \mathrm{C}$. The $\mathrm{pH}$ values at different temperatures for pure water and for standard buffer solutions are known. However, for a sample containing various dissolved species, the activity of the hydrogen ion is different than in pure water, and corrections for $\mathrm{pH}$ values as a function of temperature are virtually impossible to make without considerable experimentation and/or modelling. Ideally, the sample temperature should be maintained at about $25{ }^{\circ} \mathrm{C}$ throughout the titration.

An exception to the preparation below may be necessary for some soilwater and ground-water samples. Soil and ground waters with a partial pressure of $\mathrm{CO}_{2}$ that is greater than atmospheric may prove difficult to analyze because sample $\mathrm{pH}$ can become unstable if significant outgassing of $\mathrm{CO}_{2}$ occurs during titration. Immersing such samples in an ice bath tends to 
slow the rate of outgassing, and, in the authors' experience, will improve the reproducibility of the analyses. Such samples also can be purged with an inert gas (argon or nitrogen) for 1 to 2 hours to remove $\mathrm{CO}_{2}$ and then titrated (Lee and Brosset, 1978; Molvaersmyr and Lund, 1983). If this method of preparation is used, measurements of $\mathrm{pH}$ should be made before and after the sample is purged. Any increase in $\mathrm{pH}$ after purging may be ascribed to a loss of $\mathrm{CO}_{2}$, although for some samples other volatile acids also may be removed (Molvaersmyr and Lund, 1983). Note that $\mathrm{pH}$-electrode response may become sluggish in low-temperature solutions.

The preparation, in general, is as follows:

1. Unless the titration is done in the field, the sample should remain chilled at $4{ }^{\circ} \mathrm{C}$ until just prior to titration.

2. Bring the chilled sample to room temperature in a water bath. The length of time between removal of the sample from the refrigerator and the titration should be minimized.

3. For samples of low ionic strength, further preparation may be necessary. The lower the conductance of the water, the more difficult it may be to obtain accurate $\mathrm{pH}$ measurements. Some procedures (Lee and Brosset, 1978; Hillmann and others, 1984, p.36) add KC1 (potassium chloride) to low-conductance samples to improve the accuracy of the $\mathrm{pH}$ measurements. Such an addition may change the initial $\mathrm{pH}$ by about $0.02 \mathrm{pH}$ units, but should have no effect on the actual alkalinity or acidity value that is calculated, unless impure $\mathrm{KCl}$ is added. All reagents should be checked for purity.

\section{Calibration and Preparation of Equipment}

1. Calibrate the $\mathrm{pH}$ meter. The buffers used for meter calibration should be at the same temperature as the sample. Furthermore, because standard $\mathrm{pH}$ buffers have a higher ionic strength than many low-ionicstrength waters (such as precipitation samples), a $\mathrm{pH}$ meter and electrode calibrated with standard buffers may not measure $\mathrm{pH}$ accurately in a low- 
ionic-strength sample. Although low-ionic-strength buffers have been manufactured, and can be made by dilution of standard buffers, they generally do not have $\mathrm{pH}$ values of exactly 4 and 7 . However, some $\mathrm{pH}$ meters with automatic calibration recognize values of 4,7 , and 10 . If standard buffers are used, calibration of the meter should be checked with low-ionicstrength standard solutions. The freshness of the buffer solutions is important, especially if high-pH buffer solutions are used, as they tend to degrade fairly rapidly.

2. The equipment is set up as shown in figure 4. Rubber bands and masking tape are used to secure the equipment to the glove bag. If only alkalinity titrations are to be performed, use of the glove bag is optional for low-pH samples. Remove all bubbles from the titrant by wasting a small amount of titrant and insert the appropriate titrant cartridge into the digital titrator, as directed in the titrator methods manual. (The normality of the base titrant should be checked by titration of an acid standard, as bubbles in the titrant may signify contamination of the $\mathrm{NaOH}$ with carbonate.) To minimize the exposure of the sample to atmosphere or contaminants, the alkalinity titration may be done under nitrogen if both alkalinity and acidity titrations are to be performed. This procedure will eliminate the time required to set up the glove bag between the two titrations, as only the cartridges and delivery tube must be changed.

3. Insert the delivery tube into the cartridge. The delivery tube will leak, thereby causing measurement errors, if there is a bubble of air in the nozzle or if it is inserted too far into the cartridge. A number of drops should be dialed from the tube to expel any air or water from previous cleaning, and the exterior should be rinsed with distilled or deionized water and blotted dry. After a few minutes have elapsed, the end of the tube should be blotted again to see whether it is leaking. If it is not, then the tube is ready to be inserted into the sample.

4. Pipette the sample into a clean $100-\mathrm{ml}$ beaker containing a $12.7-\mathrm{mm}$ Teflon stirbar. If performing the titration under an inert gas, the glove must be attached to the beaker with a rubber band and the headspace purged with nitrogen before the sample is pipetted. The pipette fits through one 
finger of the glove. A spring clip is used to close that finger once the pipette has been removed. The finger into which the titrator cartridge will be inserted is left open. The nitrogen should be flowing through the bag at a low flow rate. The authors have found that a pressure reading of about 10 $1 \mathrm{~b} / \mathrm{in}^{2}$ (pounds per square inch) is sufficient to keep the glove bag inflated.

5. Insert the delivery tube and the lower part of the titrant cartridge into the open finger of the glove. The delivery tube should not be inserted into the sample until the sample $\mathrm{pH}$ has been determined. The glove finger may be attached to the titrant cartridge with masking tape. When the glove is sealed, the flow of nitrogen should be adjusted so that the glove swells gently, like a balloon, with nitrogen leaking out sufficiently slowly to keep the glove inflated. This insures that the sample remains in an inert atmosphere.

Titration and Data Analysis

1. Begin slowly stirring the sample and record the $\mathrm{pH}$. McQuaker and others (1983, p. 432) suggest that stirring low-conductance samples introduces error due to streaming potential. They recommend stirring for 15 seconds, turning off the stirrer, and allowing the $\mathrm{pH}$ reading to stabilize before recording the reading. However, this procedure increases the amount of time needed for the titration, and increases the possibility that chemical changes will take place in the sample. Changes are most likely to occur in organic-and/or trace-metal-rich waters. Stirring continuously but slowly with a micro stir bar (12.7-mm long) creates a negligible vortex.

2. Insert the delivery tube and measure $\mathrm{pH}$ again. The $\mathrm{pH}$ should not have changed more than about $0.01 \mathrm{pH}$ units. A significant change in $\mathrm{pH}$ may indicate that titrant is leaking into the sample.

3. Begin titrating the sample. Given a sample volume of $75.0 \mathrm{~m} 1$ and a titrant normality of 0.1600 , dialing 10 digits per increment usually gives reasonably small but observable changes in $\mathrm{pH}$. 
4. Titrate down to a pH of 3.0 or slightly lower for alkalinity determinations. For acidity measurements, titrate up to a $\mathrm{pH}$ of at least 11.0. In both cases, $\mathrm{pH}$ should change consistently by 0.01 to $0.02 \mathrm{pH}$ units near the conclusion of the titration.

5. Perform the necessary calculations, truncating the data set to include $\mathrm{pH}$ data from a range of $\mathrm{pH}$ values between the lowest $\mathrm{pH}$ recorded (about 3.0) and 3.5, and between about 10.5 and the highest value reached (generally greater than 11.0).

\section{Calculations}

1. If the Hach titrator is used, the digits shown on the dial are converted to volume in milliliters by dividing by 800 , or by $8 \times 10^{5}$ if the calculation is to be carried out using liters as the unit.

2. Calculate $\mathrm{F}=\left(\mathrm{V}_{\mathrm{o}}+\mathrm{V}\right) \times 10^{-\mathrm{pH}}$ for alkalinity and strong acid determinations; $F=\left(V_{0}+V\right) \times 10^{-p O H}$ for total acid determinations.

3. Regress $F$ on $V$ (volume of titrant added) for each determination.

4. Calculate the $v_{\text {eq }}$ for each determination using the equation $v_{e q}=-a / b$.

5. If acid has been added to the sample, either as a single volume or during an alkalinity titration, correct the $V_{\text {eq }}$ for strong and total acidity by subtracting $\mathrm{V} \times \mathrm{Ca} / \mathrm{Cb}$.

6. Calculate alkalinity, strong acidity, and total acidity, using the equations

$$
\begin{aligned}
& \text { Alk }=v_{\text {eq }} \times C_{a} / v_{o}, \\
& \text { Acid }_{s}=v_{\text {eq }} \times c_{b} / v_{o}, \text { and } \\
& \text { Acid }_{t}=v_{\text {eq }} \times C_{b} / v_{o} .
\end{aligned}
$$


7. Calculate weak acid: $\operatorname{Acid}_{w}=$ Acid $_{t}-$ Acid $_{\text {s }}$.

\section{Reliability of Method}

The methodology described here was evaluated using low-ionic-strength, low-pH waters sampled during a study of acid deposition in the New Jersey Pinelands (Lord and others, 1990), and on ground-water samples from elsewhere in the New Jersey Coastal Plain. Pairs of aliquots of precipitation, throughfall, surface-, soil-, and ground-water samples were analyzed. Analytical results for aliquots of precipitation, throughfall, and ground-water samples appeared to be less reproducible than did surfaceand soil-water sample pairs. The low ionic strength of both precipitation and throughfall may have affected the precision of $\mathrm{pH}$ measurements. Analyses of precipitation and throughfall samples performed during the course of this study did not include the addition of $\mathrm{KCl}$.

Slight hysteresis, ascribed to reactions involving organic matter, was observed in the alkalinity and acidity titration curves for some surfacewater samples analyzed in the study. However, such reactions apparently have little or no effect on the reproducibility of surface-water results. High organic-matter content in the soil-water samples also does not appear to affect reproducibility. One set of soil-water aliquots was purged with nitrogen to remove dissolved $\mathrm{CO}_{2}$, but no discernible improvement in reproducibility was noted.

Outgassing of $\mathrm{CO}_{2}$ from ground-water samples affected the stability of $\mathrm{pH}$ measurements, and analytical results for alkalinity from ground-water aliquots at room temperature were not readily comparable. The percent difference between room-temperature sample pairs ranged from about 66 percent to greater than 100 percent. Moderately reproducible alkalinity values (26.6 and 31.0 percent) were achieved by placing ground-water samples in an ice bath during titration. Immersing the sample in an ice bath may have been responsible for the fairly reproducible results in acidity determinations. 
In some cases, purging ground-water samples with nitrogen may improve the reproducibilty of duplicate samples. However, no such effect was observed in the ground-water aliquots analyzed. An hour of purging with nitrogen did not appear to completely remove dissolved $\mathrm{CO}_{2}$ from the sample. More work is needed to determine the most appropriate procedure for performing alkalinity and acidity titrations on ground-water samples.

Table 1 shows the percent difference, calculated as absolute value of [(sample 1 - sample 2) / ( $\left.\left.\frac{\text { sample } 1+\text { sample 2 }}{2}\right)\right] \times 100$, for duplicates analyzed. A smaller number of results for acidity titrations is shown because (1) fewer acidity measurements were made, and (2) $\mathrm{CO}_{2}$ contamination of $\mathrm{NaOH}$ titrant at the beginning of the project necessitated the deletion of questionable data. This problem was remedied by acquiring fresh titrant.

For most of the samples analyzed, alkalinity and acidity results (Lord and others, 1990) were measured in the milliequivalent range. For a few samples, the Gran calculations gave analytical results in tenths of milliequivalents or less. For such small numbers, the precision implied by the calculations is probably spurious, insofar as the $\mathrm{pH}$ meter measured to hundredths of a unit. Large percentage differences for replicates of such samples are probably acceptable, as the precision of the calculated results is questionable.

Table 2 gives ranges of $\mathrm{pH}$, specific conductance, and dissolved organic carbon for sample pairs analyzed.

In addition to the duplicate samples analyzed, four surface-water samples which were analyzed for alkalinity by Gran's technique in the Branch of Regional Research, U.S. Geological Survey, Reston, Virginia, were provided for this study. The alkalinity determinations performed in Reston employed an automated titrator. Alkalinity titrations performed using the methods described in this paper gave results of $0.74,4.4,6.2$, and 13.2 percent difference from the previously determined values. 
Table 1. Percent difference between duplicate samples

\begin{tabular}{|c|c|c|c|c|c|c|}
\hline \multirow[b]{2}{*}{$\begin{array}{l}\text { Sample } \\
\text { type }\end{array}$} & \multicolumn{2}{|c|}{ Alkalinity } & \multicolumn{2}{|c|}{ Strong acidity } & \multicolumn{2}{|c|}{ Total acidity } \\
\hline & $\begin{array}{l}\text { Number } \\
\text { sample } \\
\text { pairs }\end{array}$ & $\begin{array}{l}\text { Percent } \\
\text { difference }\end{array}$ & $\begin{array}{l}\text { Number } \\
\text { sample } \\
\text { pairs }\end{array}$ & $\begin{array}{l}\text { Percent } \\
\text { difference }\end{array}$ & $\begin{array}{l}\text { Number } \\
\text { sample } \\
\text { pairs }\end{array}$ & $\begin{array}{l}\text { Percent } \\
\text { difference }\end{array}$ \\
\hline Precipitation & 2 & $2.8-9.6$ & 1 & 12.8 & 1 & 0.8 \\
\hline Throughfall & 2 & $3.2-25.6$ & 2 & $13.2-17.2$ & 2 & $11.6-14.8$ \\
\hline Surface water & 1 & 1.6 & 1 & 7.8 & 1 & 2.8 \\
\hline Soil water & 3 & $.4-11.2$ & 2 & $1.0-1.2$ & 2 & $.6-6.8$ \\
\hline Ground water & 5 & ${ }^{1} 26.6-{ }^{2} 107.2$ & 1 & ${ }^{1} 17.6$ & 1 & 13.0 \\
\hline Total/range & 12 & $0.4-107.2$ & 6 & $1.0-17.6$ & 6 & $0.6-14.8$ \\
\hline
\end{tabular}

1 Samples placed in ice bath during titration.

2 Samples purged with nitrogen for 1 hour. 
Table 2. Range of $\mathrm{pH}$, specific conductance, and dissolved organic carbon for duplicate samples

$[\mu \mathrm{S} / \mathrm{cm}$, microsiemens per centimeter at 25 degrees Celsius; $\mathrm{mg} / \mathrm{L}$, milligrams per liter; -- indicates no analytical data]

\begin{tabular}{lcccc}
\hline Sample type & $\begin{array}{l}\text { Number } \\
\text { sample } \\
\text { pairs }\end{array}$ & $\begin{array}{c}\mathrm{pH} \\
\text { (units) }\end{array}$ & $\begin{array}{l}\text { Specific } \\
\text { conductance } \\
(\mu \mathrm{S} / \mathrm{cm})\end{array}$ & $\begin{array}{l}\text { Dissolved } \\
\text { organic } \\
\text { carbon } \\
\text { (mg/L) }\end{array}$ \\
\hline precipitation & 1 & 4.5 & 25 & - \\
throughfall & 2 & $4.1-4.4$ & $52-93$ & $9.7-11.0$ \\
surface water & 1 & 3.5 & 285 & 17.0 \\
soil water & 3 & $4.0-4.1$ & $36-49$ & $12.0-21.0$ \\
ground water & 5 & $4.7-5.0$ & $23-261$ & .5 \\
\hline
\end{tabular}


The limitations of some conventional techniques make the Gran technique for alkalinity and acidity determinations a preferred method for the analysis of low-pH, low-ionic-strength waters. The procedure described here is a simplification of the Gran technique that can be performed easily and inexpensively. The method is reliable for a variety of water sources, and precision appears to increase with increased specific conductance and decreased dissolved $\mathrm{CO}_{2}$ content.

The successful application of Gran's technique to low-pH, low-ionicstrength natural waters may be limited by the chemistry of a given water sample. Meaningful interpretation of the analytical results depends on a full understanding of the sample chemistry and the interferences that can occur. In particular, interpretation of data from waters containing high levels of organic matter and/or hydrolyzable metals may require knowledge of the groups of organic acids and the particular metal species present. Geochemical modeling combined with the Gran technique also should prove useful to interpret analytical results. 
Cosby, B. J., Hornberger, G. M., Galloway, J. N., and Wright, R. F., 1985, Modeling the effects of acid deposition: Assessment of a lumped parameter model of soil water and streamwater chemistry: Water Resources Research, v. 21, p. 51-63.

Drever, J. I., 1982, The geochemistry of natural waters: Englewood Cliffs, N.J., Prentice-Hall, Inc., 388 p.

Driscoll, C. T., 1984, A procedure for the fractionation of aqueous aluminum in dilute acidic waters: International Journal of Environmental Analytical Chemistry, v. 16, p. 267-283.

Driscoll, C. T., and Bisogni, J. J., 1984, Weak acid/base systems in dilute acidified lakes and streams of the Adirondack region of New York State, in Schnoor, J. L., ed., Modeling of total acid precipitation impacts: Acid Precipitation Ser.- v. 9, Boston, Ma., Butterworth Publishers, p. $53-72$.

Fishman, M. J., and Friedman, L. C., 1985, Methods for determination of inorganic substances in water and fluvial sediments: Techniques of Water-Resources Investigations of the United States Geological Survey, book 5, chap. A1, $626 \mathrm{p}$.

Galloway, J. N., Schofield, C. L., Hendry, G. K., Peters, N. E., and Johannes, Arland H., 1983, Lake acidification during spring snowmelt, In The intergrated lake-watershed acidification study: Proceedings of the ILWAS Annual Review Conference, EA 2827 Research Project 1109-5, Electric Power Research Institute, Palo Alto, Ca., p. 10-4 and 10-18.

Gran, Gunnar, 1952, Determination of the equivalence point in potentiometric titrations, Part II: The Analyst, v. 77, p. 661-671.

Greenberg, A. E., Connors, J. J., Jenkins, David, and Franson, M. A. H., eds., 1981, Standard methods for the examination of water and wastewater, 15th edition: American Public Health Association, Washington, D. C., 1134 p.

Hillmann, D. C., Morris, F. A., Potter, J. F., Cabell, K. G., and Simon, S. J., 1984, A methods manual for the National Surface Water Survey Project-- Phase I, February 15, 1984: United States Environmental Protection Agency, $127 \mathrm{p}$.

Johansson, Axel, 1970, Automatic titration by stepwise addition of equal volumes of titrant, Part I. Basic principles: The Analyst, v. 95, p. $535-540$.

Johnsson, P. A., and Lord, D. G., 1987, A computer program for geochemical analysis of acid-rain and other low-ionic-strength acidic waters: U.S. Geological Survey Water-Resources Investigations Report 87-4095, 42 p. 
Keene, W. C., and Galloway, J. N., 1985, Gran's titrations: Inherent errors in measuring the acidity of precipitation: Atmospheric Environment, v. 19, p. $199-202$.

Lee, Ying-Hua, and Brosset, Cyril1, 1978, The slope of Gran's plot: A useful function in the examination of precipitation, the water-soluble part of airborne particles, and lake water: Water, Air, and Soil Pollution, v. 10, p. 457-469.

Lindberg, S. E., Coe, J. M., and Hoffman, W. A., 1984, Dissociation of weak acids during Gran plot free acidity titrations: Tellus, v. 36B, p. $186-191$.

Lord, D. G., Barringer, J. L., Johnsson, P. A., Schuster, P. F., Walker, R. L., Fairchild, J. E., Sroka, B. N., and Jacobsen, Eric, 1990, Hydrogeochemical data from an acidic deposition study at McDonalds Branch in the New Jersey Pinelands, 1983-1986: U.S. Geological Survey Open-File Report 88-500, 132 p.

McKnight, Diane, Thurman, E. M., Wershaw, R. L., and Hemond, Harold, 1985, Biogeochemistry of aquatic humic substances in Thoreau's Bog, Concord, Massachusetts: Ecology, v. 66, p. 1339-1352.

McQuaker, N. R., Kluckner, P. D., and Sandberg, D. K., 1983, Chemical analysis of acid precipitation: $\mathrm{pH}$ and acidity determinations: Environmental Science and Technology, v. 17, p. 431-435.

Molvaersmyr, K., and Lund, W., 1983, Acids and bases in fresh waters. Interpretation of results from Gran plots: Water Resources, v. 17, p. $303-307$.

More1, F. M. M., 1983, Principles of aquatic chemistry: New York, N.Y., John Wiley and Sons, $446 \mathrm{p}$.

Oliver, B. G., Thurman, E. M., and Malcolm, R. L., 1983, The contribution of humic substances to the acidity of colored waters: Geochimica et Cosmochimica Acta, v. 47, p. 2031-2035.

Pagenkopf, G. K., 1978, Introduction to natural water chemistry: Environmenta1 Science and Technology Series: v. 3, New York, N.Y., Marce1 Dekker, Inc., 272 p.

Peters, D. G., Hayes, J. M., and Hieftje, G. M., 1974, Chemical separation and measurement, in Theory and practice of analytical chemistry: Philadelphia, Pa., W. B. Saunders, 379 p.

Plummer, L. N., Jones, B. F., and Truesde11, A. H., 1978, WATEQF--A FORTRAN IV version of WATEQ, a computer program for calculating chemical equilibrium of natural waters: U. S. Geological Survey Water-Resources Investigations Report 76-13, $61 \mathrm{p}$. 
Stumm, Werner, and Morgan, J. J., 1981, Aquatic chemistry, 2nd edition: New York, N.Y., Wiley-Interscience, John Wiley and Sons, 780 p.

Thurman, E. M., 1985, Organic geochemistry of natural waters: Dordrecht, Martinus Nijhoff/Dr. W. Junk, 497 p.

Thurman, E. M., and Malcolm, R. L., 1981, Preparative isolation of aquatic humic substances: Environmental Science and Technology, v. 15, no. 4, p. $463-466$.

Tyree, S. Y., 1981, Rainwater acidity measurement problems: Atmospheric Environment, v. 5, p. 57-60.

Weast, R. C., Astle, M. J., and Beyer, W. H., eds., 1988-1989, CRC Handbook of chemistry and physics, 69th edition: Boca Raton, Fla., CRC Press, Sections A - F. 